\title{
Investigating the Relationship between Positive Self-Concept and Success of Academic Staffs at University of Guilan, Iran
}

\author{
Abbas Sadeghi' ${ }^{1}$, Setareh Azizi' ${ }^{2}$, Samane Moosa Poor ${ }^{3}$ \\ ${ }^{1}$ Department of Educational Sciences and Counselling, University of Guilan, City of Rasht, Iran \\ ${ }^{2}$ Department of Clinical Psychology, Free University of Guilan, City of Rasht, Iran \\ ${ }^{3}$ Department of General Psychology, Free University of Guilan, City of Rasht, Iran \\ Email: Asadeghi1394@gmail.com, setarehazizi2@gmail.com
}

Received 9 November 2015; accepted 29 December 2015; published 31 December 2015

Copyright (C) 2015 by authors and Scientific Research Publishing Inc.

This work is licensed under the Creative Commons Attribution International License (CC BY). http://creativecommons.org/licenses/by/4.0/

cC) (i) Open Access

\begin{abstract}
The purpose of this research was to investigate the relationship between positive self-concept and success academic staffs at University of Guilan where 281 out of 500 contractual, official-experimental and official academic staffs were selected by simple random sampling in 2014-2015 academic year. The amount of effectiveness of factors such as academic staffs' responsibilities, risk taking, strong self-concept (feeling of merit and evaluation) on their position has been measured in this research. Research questions have also measured manager's personal traits (gender, age, and education level, field of study, work experience and teaching experience). For collecting information of this research which is correlation type, two questionnaires with 51 questions have been used in Likert spectrum. The results showed that there is a significant relationship between positive self-concept and success of academic staffs' variables and personal traits which are female and male academic staffs' education degree, work experience, professional experience and faculty. Also, behavioral sciences academic staffs (psychology, counseling and social sciences) generally had higher positive self-concept.
\end{abstract}

Keywords

Self-Concept, Attitude, Success

\section{Introduction}

It seems that academic self-concept focuses on the imagination of the capability in an academic location and so-

How to cite this paper: Sadeghi, A., Azizi, S., \& Poor, S. M. (2015). Investigating the Relationship between Positive Self-concept and Success of Academic Staffs at University of Guilan, Iran. Psychology, 6, 2155-2160.

http://dx.doi.org/10.4236/psych.2015.616212 
cial self-concept concentrates on the individual situation. Different factors and phenomenon influence human success. One of the most effective factors on human success is his/her attitude and viewpoint towards himself/ herself. As we have some assumptions about humans and other phenomenon, and based on our past experience, we compare them differently. We also have different assumptions about ourselves. Self-concept is an assumption that individuals have from their own evaluation which includes a mixture of their emotions, general view towards our social acceptance and their emotions toward themselves.

Self-concept develops as the result of person experience with environment and his/her assessing from these experiences. Moreover, noticeable opinions of others, casual features and real feedback play important role in the process of self-concept development (Sternco, 2010). Also, positive selfishness is a sweet and desirable emotion that enables human to be inform from his/her tendencies and desires, accepts his/her perfection without any rules and conditions, and demands his personal rights by recognizing his/her actions (Neynavaei, 1996).

Some people probably have special ability but because of failure in the past, they assume themselves as unable and some others consider the ability less or more than the reality. As academic staffs do the same things, maybe their viewpoint from themselves can be effective in their extent of success or failure in teaching and finally in students' academic improvement. Regarding to this point that change and innovation at university are necessary, stereotype and fixed thoughts are obstacles to students and professors' improvement and prevent from accepting necessary changes and innovation and ignore new and useful thoughts (Stephen, 1991).

Most of the times, a mixture of two or more things can create new phenomenon. In fact, creativity is the ability of creating new forms. In many higher education organizations that professors believe in their abilities and are eager to students' participations in decision making, responsibility and authority, extent of creativity and responsibility are meaningful.

Saeediyan \& Nili (2012) investigated the relationship among emotional intelligence, self-efficacy and selfconcept and the results showed that there was a meaningful relationship among these three categories, that was individuals who had high self-concept and positive assessment from their abilities had higher efficacy, that was to have higher score in personal skills than those persons who had less self-concept and their amount of compatibility was better. Neinavaei (1996) believes that success in work depends on having stored information and ability to interact and understand others. A person who doesn't put evaluation in his job position always boasts about works he did in the past and shows himself important. In fact, by doing this, they build a big wall in front of themselves that nobody can near them and understand their reality.

Rahimi-Nezhad \& Beheshtifar (2012) mentioned that self-concepts are recognition patterns which can include content, attitude or valuation judgment and are used for giving meaning to the world, concentrating on person's goals and supporting person basic valuations.

Self-concept of each person determines and controls the scope of that person's activity in life (Salimi, 2001). Positive self-concept increases by encouraging to successful works, valuation for admirable activities and providing self-test opportunity to them (Salimi, 1987). Relationship between clarity of cultural identity and also self-confidence and welfare is mediated by clarity of self-concept (Usborne \& Taylor 2010). Person's assumption from his personality determines his view about his environment and this factor plans his type of behavior. If assumption from ourselves is positive and fairly balanced, person hasn't mental health; and inverse if person's self-concept is negative and unbalanced, he is known unhealthy from mental viewpoint (Biyabangard, 1997).

According to Farrar, Stopa, \& Turner (2015), holding a negative self-image in mind had a negative effect on explicit self-esteem, whilst holding a positive self-image had a beneficial effect. There were no effects of imagery on implicit self-esteem. Holding a negative image in mind led to a significant reduction in self-concept clarity; however, positive self-imagery did not affect self-concept clarity. Holding a negative self-image in mind led to a decrease in body satisfaction and state affect. The opposite was found for the positive self-imagery group. Self-imagery in individuals with high body dissatisfaction: The effect of positive and negative self-imagery on aspects of the self-concept. Fostering social and academic self-concepts are central educational goals. Relations among academic self-concept, social self-concept, and academic achievement were investigated. Their Results indicate that fostering adolescents self-concept in social and academic domains are compatible goals. However, some students need support in managing the challenge to coordinate social and academic goals (Preckel et al., 2013). According to (Church et al., 2012), the results provide support for integrating trait and cultural psychology perspectives, as well as structure and process approaches, in the study of self-concepts across cultures. Disterheft et al. (2015) mentioned the success of participatory approaches is interdependent with structural institutional conditions and the persons engaged, highlighting the importance of specific skills and 
participatory competencies. A better integration of the dimensions of participation into sustainability assessment practices can help in defining and establishing participatory approaches on institutional level and fostering a culture of participation in the transition to sustainable universities. Cserháti \& Szabó (2014) analysis of the correlations suggests that relationship-oriented success factors, such as communication, co-operation and project leadership, play a crucial role in carrying out successful organizational event projects. Self-concept is one of the most important successful factors in human life. If a person knows his/her abilities and talents and has positive assumption and view from his/her abilities and believes that can achieve to things that has talent, results in his/her improvement. Regarding to professors' self-concept, their attitude towards themselves has special importance in teaching and learning process, because this results in identifying their abilities, talent, interests and motivations that impacts.

Although conducted researches in MM and character still remains in elementary periods, most researches on both implicit and explicit levels, guarantee the work on aspects such as feeling of responsibility, authority, compassion, and acceptance, this form of psychological nurturing can lead person's character to more coherent and healthier emotion than himself and his identity.

Positive academic self-concept has been considered one of the most important indicators of educational success. Empirical evidence across divergent educational and cultural contexts supports 1) a hierarchical multidimensional model of self-concept; 2) reciprocal causal relations between academic achievement and corresponding self-concepts; 3) the use of both internal and external frames in making self-concept judgment; and 4) the importance of both social comparison and reflected glory effects (Hau \& Marsh 2015).

By using this research results, academic staffs can have a type of review in sort of attitude and viewpoint, that be effective on students with positive and high view and self-concept in themselves and with this knowledge and change in themselves and students provide more effectiveness and success in achieving higher education goals. Achieving to efficiency and improving the quality of education system is the most effective factor in countries development. The most important task of education system is to prepare students for achieving knowledge, recognition and job skills for going to society and attention to their training from education, research and cultural viewpoint is significantly important. Academic success depends on different factors that we can point out to some of them such as personal, social, academic and psychological factors and self-concept is reciprocally linked to academic achievement, implying that achievement results underlie the formation of related self-concepts, and that self-concepts in turn influence motivation, the effective factor on success. Beyond academic self-concepts, education at home and in academic institutions also influences students' general self-esteem. Important educational factors affecting general self-esteem as well as more specific self-concepts are acceptance by significant others (e.g., parents and teachers), consistent behavioral rules, support of autonomy, academic instruction, and feedback on abilities, behavior, and achievement. Of specific importance is reference norms used for giving feedback (e.g., social comparison vs mastery-oriented norms).

\section{Methodology}

\subsection{Participants}

The population was all academic staff members in the University of Guilan, Iran. 281 out of 500 contractual, official-experimental and official academic staffs were selected by simple random sampling in 2014-2015 academic year. The demographic characteristics of the 281 academic staffs are as follows:

The gender of participants is 24 Male \& 41 Female and the age of them is 99 under 30, and 182 after 30. also 25 of them are lecturers, 151 assistant professors, 80 associate professors and 20 full professors.

\subsection{Procedures}

300 questionnaires have been distributed through a face to face appointment the samples with a 5 minutes explanations.

The return number of questionnaires was 281.

\subsection{Instruments}

Two different researchers made questionnaire have been used as a self-concept questionnaire with 25 items and successful questionnaire with 20 items. The reliability of these questionnaires calculated through a pilot study as 
$88 \%$ and $91 \%$. Also, the validity of the questionnaire has been considered by correcting 3 academic staff members' modifications in counselling, educational sciences and social sciences.

\subsection{Data Analysis}

Due to the finding of the relationship between the variables, the correlation coefficient has been used as data analysis method.

\section{Results}

Hypothesis (1):

There is a relationship between, academic staffs' attitude and their success.

According to Table 1, there is a high correlation between attitude and success in reverse level (with more attitudes toward ourselves, the amount of success decreases).

It seems because the respondents are less experienced academic staffs toward items related to attitude (dependent variable), and because of not having perfect familiarity with professors' attitude and insufficient knowledge from success factors, most of them select weak items and this results in getting reverse results. Probably if responding to items related to dependent variable was conducted by experienced academic staffs, it would results in positive results.

Hypothesis (2):

There is a relationship between academic staffs' personality and their success.

According to Table 2, there is a high correlation between personality and success in reverse level. That is, with more feeling of personality, the amount of success decreases.

Hypothesis (3):

There is a relationship between taking responsibility of academic staffs and their success.

According to Table 3, there is a high correlation between taking responsibility and success in reverse level that is with more feeling of taking responsibility, the amount of success decreases.

Table 1. Relationship between attitude and success.

\begin{tabular}{cccc}
\hline Number of respondents & Sig. level & Attitude & \\
\hline 281 & 0.00 & 0.943 & Success \\
\hline
\end{tabular}

Table 2. Relationship between personality and success.

\begin{tabular}{cccc}
\hline Number of respondent & Sig. level & Personality & \\
\hline 281 & 0.00 & 0.982 & Success \\
\hline
\end{tabular}

Table 3. Relationship between taking responsibility and success.

\begin{tabular}{cccc}
\hline Number of respondents & Sig. level & Taking responsibility & \\
\hline 281 & 0.00 & -0.986 & Success \\
\hline
\end{tabular}

Table 4. Relationship between risk taking and success.

\begin{tabular}{ccc}
\hline Number of respondents & Sig. level & Risk taking \\
\hline 281 & 0.00 & -0.950 \\
\hline
\end{tabular}

Table 5. Relationship between feeling of merit and success.

\begin{tabular}{ccc}
\hline Number of respondents & Sig. level & Feeling of merit and valuation \\
\hline 281 & 0.00 & -0.975 \\
\hline
\end{tabular}


Hypothesis (4):

There is a relationship between academic staffs' risk taking and their success in teaching (look at Table 5).

According to Table 4, there is a high correlation between risk taking and academic staffs' success in reverse level. That is, with more risk taking, the amount of success decreases.

Hypothesis (5):

There is a relationship between professors' merit and valuation and their success in teaching.

According to Table 5, there is a high correlation between feeling of merit and valuation and academic staffs' success in reverse level. That is, with feeling of merit and valuation, the amount of success decreases.

\section{Discussion and Conclusion}

The results show that there is a meaningful difference between academic staffs' self-concept and attitude with their success in reverse level. It also shows that there is a meaningful difference between professors' self-concept and their success with features of demographics. Personality is a series of mental features that exist permanently in person and effect on his behavior and thoughts. Subjects' personality type is very important in job compatibility. Agreement between personality type and environment type causes more compatibility with job and profession that brings satisfaction (Shafieeabadi, 1997-1999). In the third hypothesis, there is a relationship between academic staffs' taking responsibility and their success in teaching.

Achieved results from $\mathrm{T}$ test table indicate that there is a difference between taking responsibility and teaching success in reverse level. As we can define taking responsibility as a necessary and inner commitment from person for doing all activities that are put on him, we can demonstrate that taking responsibility results are from the inside of person and there is a reciprocal relationship between taking responsibility and success. The last probability is that many people think because they have reached to adult age, and can't do anything for supporting this feature, so the probability of bias exists in responding.

In the fourth hypothesis, there is a relationship between professors' risk taking and their success.

Whitley (2000) points out that successful persons are innovative in their works and have risk taking ability for improving creativity and innovation. Creative managers follow ambitious goals, they are risk takers and do works that are amazing for the first time and at the same time have reasonable risk.

In the fifth hypothesis, there is a positive relationship between managers' feeling of merit and valuation and their success in management, that is with more strong concepts and feeling of merit, their success increases with the same amount. The results of the statistical methods showed a significant relationship with the technological component of knowledge management, a significant difference between the present situation component with the desired components and different priorities influencing factors in knowledge management (Kheyrandish et al., 2011).

Therefore, with regard to presented reasons, it is recommended to future researches that for getting more real results, it is better to pay more attention and for assessing factors related to dependent variable, which is success, selecting the respondents from professors' society of all universities and colleges not only two colleges or one university. Also it is offered that pay more attention to selection of items for assessing factors. It is possible that individuals have noticed to inner factors like feeling of merit and self-valuation as a criterion for success and give less attention to it, so it is recommended to emphasis on the role of inner factors.

Regarding to the research results, authorities and colleagues of higher education system should prepare the conditions for employing and applying qualitative forces and experts to prevent from academic staffs' negative entropy by preparation and proper readiness and take action for retraining the professors, improvement of their lifestyle and work condition, financial and spiritual support, using modern teaching and technology, sanitation and equipment of physical facilities for inactivating successful preventive forces.

Also, it seems that most of the academic staffs are not satisfied with their performance. So it is recommended to review some scientific and motivated conditions of academic staffs and revise toward change or revision of academic staffs' employment instructions and all academic staffs suffer from disorganized economic situation; and they don't have enough salary, this issue has negative effect on their performance and brings negative results for person and university. So it is recommended to take good action for decreasing this problem. Momen et al. (2005) focused education in the form of a course and relied more on practical training besides theoretical and concrete matters of theory through the use of teaching aids and facilities skill lab during semiology that led to satisfaction rate of this method of teaching and this method was more effective. 
It's recommended to higher education authorities to increase human relationships and spirit of participation in academic staffs' decision making by holding in service classes and providing appropriate facilities and training work motivations. And in addition to creating motivation by holding some classes, let the professors be familiar with proper research methods and encourage them to research by giving rewards and providing financial and spiritual support to researches. For the sake of relationship between self-concept and managers' success, it is recommended to notice to managers' performance more and help them to achieve higher education goals and increase success and give more authority in the case of their responsibilities.

Meanwhile, because of relationship between self-concept and academic staffs' success, it is recommended to care more to ability and talent of successful professors in the case of feeling of merit and valuations, and give more motivation in work and attempt by their improvement in more responsibilities, give more responsibilities and authorities to academic staffs, and increase their risk taking and bravery in solving school problems and their success in management.

Notice to self-concept and its reinforcement in academic staffs' cause academic and scientific improvement in students and benefit from achieved results from other universities for reinforcing professors' self-concept.

Finally, academic staffs' knowledge from self-concept notion increases their performance and feedback, and then classroom feedback; and it is recommended professors of different academic groups to be aware of information and scientific theories and to apply them in controlling classroom by permanent study.

\section{References}

Biyabangard, E. (1997). Way of Increasing Self-Confidence in Children and Adolescence (4th Ed.). Parents and Instructors Committee of Islamic Republic of Iran, Tehran.

Cserháti, G., \& Szabó, L. (2014). The Relationship between Success Criteria and Success Factors in Organizational Event Projects. International Journal of Project Management, 32, 613-624. http://dx.doi.org/10.1016/j.ijproman.2013.08.008

Church, A. T., Alvarez, J. M., Katigbak, M. S., Mastor, K. A., Cabrera, H. F., Tanaka-Matsumi, J., de Jesús Vargas-Flores, J., Ibáñez-Reyes, J., Zhang, H.-S., Shen, J. L., Locke, K. D., Ortiz, F. A., Curtis, G. J., Simon, J.-Y. R., Ching, C. M., \& Buchanan, A. L. (2012). Self-Concept Consistency and Short-Term Stability in Eight Cultures. Journal of Research in Personality, 46, 556-570. http://dx.doi.org/10.1016/j.jrp.2012.06.003

Disterheft, A., Caeiro, S., Azeiteiro, U. M., \& Filho, W. L. (2015). Sustainable Universities-A Study of Critical Success Factors for Participatory Approaches. Journal of Cleaner Production, 106, 11-21.

http://dx.doi.org/10.1016/j.jclepro.2014.01.030

Farrar, S., Stopa, L., \& Turner, H. (2015). Self-Imagery in Individuals with High Body Dissatisfaction: The Effect of Positive and Negative Self-Imagery on Aspects of the Self-Concept. Journal of Behavior Therapy and Experimental Psychiatry, 46, 8-13. http://dx.doi.org/10.1016/j.jbtep.2014.07.011

Momen, H. M., Ismail, F., \& Elahe, M. R. (2005). Semiology upon a Change of Course in Education. Special Seventh National Conference on Medical Education, Volume 5, Issue Appendix 14.

Hau, K.-T., \& Marsh, H. W. (2015). Academic Self-Concept and Achievement. In International Encyclopedia of the Social \& Behavioral Sciences (2nd ed.). American Psychological Association, 54-63

Kheyrandish, M., Doostkam, K., \& Hsynayy, Y. (2011). The Role of Technological Factors in the Success of Knowledge Management. Management System, 11, 69-88.

Neynavaei, Z. (1996). Self-Confidence or Viewpoint (Golshan Edition). Tehran: Neday Farhang Press.

Preckel, F., Niepel, C., Schneider, M., \& Brunner, M. (2013). Self-Concept in Adolescence: A Longitudinal Study on Reciprocal Effects of Self-Perceptions in Academic and Social Domains. Journal of Adolescence, 36, 1165-1175.

Rahimi-Nezhad, Z., \& Beheshtifar, M. (2012). Role of Self-Concept in Organizations. European Journal of Economics, Finance and Administrative Sciences, Issue 44, 159-164.

Salimi, M. (2001). Translation of Planning Innovation Book in Education. Paris: UNESCO.

Salimi, G. (1987). Self-Concept and Its Role in Children Training. Tehran: Payvand, Parents and Instructors Committee Press.

Saeediyan, F., \& Nili, M. (2012). Investigating the Impact of Training Assertiveness on Social Compatibility and Positive Self-Concept of Females Head of Households.

Sternco, J. C. (2010). Self-Concept and Self-Esteem in Adolescents with Learning Disabilities.

Usborne, E., \& Taylor, D. M. (2010). The Role of Cultural Identity Clarity for Self-Concept Clarity, Self-Esteem, and Subjective Well-Being.

Whitley, D. (2000). Victory Psychology (Translation of Ali Shaghayegh). Tehran: Kavir Press. 